\title{
Cultural Orientation and Culture Consumption Outcomes: Comparing Immigrants from the Former Soviet Union to Israel and Germany-An Abstract
}

\author{
David Dose, Gianfranco Walsh, Ayalla A. Ruvio, and Sigal Segev
}

\begin{abstract}
The ever-increasing immigration worldwide compels marketers to understand how a new mainstream culture that embeds immigrant consumers might shape their consumption behavior. Specifically, this study examines whether minority groups of the same cultural heritage, living in different countries, vary in their cultural orientations (i.e., mainstream vs. heritage cultural orientations) and consumption outcomes (i.e., desire for unique products and fashion consciousness). A proposed model and hypotheses were tested in two samples of Russian-speaking adults from the former Soviet Union (FSU) who migrated to either Israel or Germany. Results from a survey indicate that FSU immigrants show a stronger orientation to their heritage culture in Israel and stronger pattern orientation toward the mainstream culture in Germany. In turn, these cultural orientations affected immigrants' consumption preferences. These results confirm that the cultural orientations of the same immigrant group can differ across countries, which can be explained by contextual factors such as the differences in the immigration history and policies of the receiving countries. Theoretical and managerial implications are further discussed.
\end{abstract}

References available upon request.

D. Dose $(\bowtie) \bullet$ G. Walsh

Friedrich-Schiller-University of Jena, Jena, Germany

e-mail: david.dose@uni-jena.de; walsh@uni-jena.de

A.A. Ruvio

Michigan State University, East Lansing, MI, USA

e-mail:ruvio@broad.msu.edu

S. Segev

Florida International University, Miami, FL, USA

e-mail: segevs@fiu.edu 